\title{
CORRESPONDENCE
}

In a letter dated April 22, 2013, Dr. Werner Apt B, from Chile, commenting on a paper published in our Journal: GIL, F.F.; BARROS, M.J.; MACEDO, N.A.; JÚNIOR, C.G.E.; REDOAN, R.; BUSATTI, H.; GOMES, M.A. \& SANTOS, J.F.G. - Prevalence of intestinal parasitism and associated symptomatology among hemodialysis patients. Rev. Inst. Med. Trop. Sao Paulo, 55(2): 69-74, March-April, 2013, raised an interesting point of view regarding intestinal parasitism of Endolimax nana and Entamoeba coli, both so far considered non-pathogenic for the host, and apparently listed as such in Tables presented by the Authors.

Responses to the question by the authors and the referees of the paper were as follows:

\section{RESPONSES OF THE AUTHORS}

Belo Horizonte, May 02, 2013

You can find below the answer to the questions raised by Prof. Werner Apt B. However, first of all we would like to make clear here our constraint in relation to the impolite way that this professor has referred to our work and also to reviewers. The issues raised by him are very basic, but we'll try to answer them below satisfactorily.

As concepts widely disseminated in scientific literature and adopted by WHO: Parasites are organisms that live in association with others, including withdrawing the means for their survival. Still, parasitism is an ecological relationship, developed between individuals of different species, in which there is, in addition to an intimate association, metabolic dependence of a different degree. Among the definitions of the degree of relatedness between species, these may be pathogenic or commensal, or have a positive relationship for both species, which is called mutualism.

These concepts, which are adopted by WHO, are useful from the epidemiological point of view, because many commensal parasites are markers of environmental conditions and behavior, facilitating infection by others non commensal with the same routes of infection. Thus, unambiguously, we have described correctly and relevantly all terms, in the text, as in the tables, consequently both Entamoeba coli and Endolimax nana are enteroparasites.

The presentation of commensal and not commensal parasites in the table that assesses symptoms was questioned. This question is not relevant, considering the population studied, which involved renal chronic failure patients in stage $\mathrm{V}$ on hemodialysis. In this context, in the manuscript we accentuate the disease-health process, considering the pathogenesis of diseases and immunity alterations that can lead to changes in the relationship between host and parasite, which makes the occurrence of disease by commensal possible. We emphasize further, that this argument was the main prerequisite for the study, described explicitly in the text, where we show our concern with behavior of intestinal parasites in a group so immunologically vulnerable.

We understand that we can expect parasites to behave as commensal in immunocompetent individuals as much as they can present themselves as pathogenic ones in immunocompromised patients, and may even exacerbate symptoms of primary disease, which not only justifies the presentation of tables as published, but is also imperative in this type of reporting.

Yours sincerely,

Joseph F. G. Santos

\section{RESPONSE OF REFEREE 1}

May 15, 2013

Most of the terms employed to define the interspecific ecological relationships were proposed in a period when little knowledge of physiology and biochemistry were available so that these associations could be considered on a broader scale. In this way, there are some aspects that have to be considered in any ecological association to understand their differences. Among these aspects, the metabolic dependence must be stressed as one of the most relevant. So, considering this point, the term commensalism represents "a loose type of association in which two organisms of different species live together without either being metabolically dependent on the other, although one or both organisms may receive some benefit from the association". Here, it is important to highlight that the absence of "metabolic dependence" is the feature that separates a commensal organism markedly from a parasite organism. In this context, the metabolic dependence can be broader than only that concerning nutritional requirements, the most common form of this kind of dependence. Thus, parasites can be dependent on their hosts for nutritional supplies and/or, e.g., the following aspects: (1) developmental stimuli; (2) digestive enzymes; (3) control of maturation; (4) particular host environments suitable to complete the life cycle. In addition, other important points are that the degree of metabolic dependence of a parasite on its host depends on the parasite species and a parasite organism is not necessarily harmful to the host.

Thus, considering the aspects above, Entamoeba coli and Endolimax nana are a parasitic protozoan, but non-pathogenic species. So, the inclusion of these amoebae on the tables mentioned by Dr Weber Apt was not unsuitable. Beside these amoebae, among non-pathogenic intestinal parasites, Iodamoeba bütschlii and Blastocystis hominis are also common species detected in coproparasitological surveys. In recent manuscripts published in reputable journals, these protozoans have been referred to as non-pathogenic parasites and have been included in tables with other intestinal parasites species, as can be noted, for instance, in the following papers: (1) SPEICH B, et al. Parasites \& Vectors, 2013,6:3; (2) SHOBHA M, et al., Journal of Infection and Public Health, 2013,6:142-149; (3) COULIBALY JT, et al., Parasites \& Vectors, 2012,5:135.

We hope that with these considerations, we can reply satisfactorily to the issues raised by Dr. Weber Apt.

\section{RESPONSE OF REFEREE 2}

Regarding the letter from Dr. Werner Apt B., about the article entitled "Prevalence of intestinal parasitism and associated symptomatology 
among hemodialysis patients", whose authors are Frederico F. GIL et al., I have some comments to make, which are as follows:

Dr. Apt pointed out a serious mistake in this article, since organisms such as Endolimax nana and Entamoeba coli were included in the article mentioned above as "intestinal parasites" and the traditional parasitology view classifies them as commensals. However, the pathogenesis of $E$. nana for humans has been a very controversial issue. Some authors argue that it is a commensal of the human gut, not having invasive ability and not causing any pathology to individual health. So, the finding of value of E. nana on a parasitological stool test would be an epidemiologic indication of fecal-oral contamination. This point of view is presented on CDC/USA (Centers for Disease Control and Prevention, USA) (http://www.dpd.cdc.gov/dpdx/HTML/IntestinalAmebae.htm).

On the other hand, there are certain circumstances that affect the man's immune system, such as the case of patients with chronic renal failure undergoing hemodialysis (TRANAEUS A \& YAO Q, Peritoneal Dialysis International, 2008;28(Suppl 3):S161-S166), which is also the case in the study of Frederico F. GIL et al. published in RIMTSP. In these patients, the pathogenicity of E. nana is well known (AZAMI M, et al., Brazilian Journal of Infectious Diseases, 2010;14:15-18; KULIK RA, et al., Brazilian Journal of Infectious Diseases, 2008;12:338-341).

In the study of KULIK et al., patients with chronic renal insufficiency submitted to hemodialysis and reporting diarrhea, $E$. nana were found in $16 \%$ of them and co-infection with Blastocystis hominis occurred in $21 \%$ of the patients sampled. These authors and GRACZYCK TK, et al. (Parasitological Research, 2005;98:38-43,) pointed out that gastrointestinal symptoms from $E$. nana infection occur and also, that there is subsequent irritation of the intestinal mucosal crypts leading to fibrosis. Furthermore, E. nana infection has been reported as a cause of acute diarrhea in children. It happens due to immature immune systems of infants, as stated by GRACZYCK et al., and poor sanitized conditions.

The stool of schoolchildren tested in Zambia showed that the only organisms associated with diarrhea were E. nana $(64.3 \%)$ and B. hominis $(53.8 \%)$. GRACZYCK et al. concluded that there is a significant association among these organisms and diarrhea in children when they occur at high prevalence and intensity. Another study also reported the co-infection with $E$. nana and B. hominis resulting in chronic diarrhea in an immunocompetent man (SHAH M, et al., Case Rep. Gastroenterology, 2012;6:358-364), and this case illustrates that clinicians should be conscious that both E. nana and B. hominis infections may be a cause of chronic diarrhea in an immunocompetent host. STAUFFER JQ \& LEVINE WL (American Journal of Digestive Diseases, 1974;19:59-63) described chronic diarrhea in a patient infected exclusively with this organism. Although tissues invasion could not be demonstrated, the response with metronidazole was dramatic and circumstantially implicates E. nana as causing the diarrhea.

In the last years, "urticarias" and arthritis rheumatoid-like symptoms were associated to the E. nana infections in immunocompetent patients (VERALDI S, et al., International Journal of Dermatology, 1991;30:376; BURNSTEIN SL \& LIAKOS S, Journal of Rheumatology, 1983;10:514-
515; CONTRERAS-FERRER P, et al., PIEL (Barc.), 2012;27:175-177). In my opinion, the clinical relevance of $E$. nana in immunocompetent individuals is not clear and deserves more attention.

CORCORAN GD, et al. (Lancet, 1991;338:254,) and also WAHLGREN M (Lancet, 1991;337:675) related the case of two girls with Entamoeba coli and gastrointestinal symptoms (abdominal pain, loose bowel motions, cramps and intermittent diarrhea). No other pathogens were detected in the stool test. After metronidazole treatment, one child showed resolution of symptoms and Ent. coli cysts were not detected in follow-up stool examination during six weeks. The other girl despite of metronidazole treatment (five day course) showed mild symptoms and small number of $E$. coli cysts in feces. According to these authors the detection of large numbers of cysts in feces in association with abdominal symptoms might be relevant. HOTEZ P (Seminars in Pediatric Infectious Diseases, 2000;11:178-181) comments: "E. coli was always considered an entirely nonpathogenic enteric protozoan until 1991, when case reports appeared in northern Europe suggesting otherwise".

Recently, KIRAN TR, et al. (HealthMED, 2012;6:2108-2111) verified the level of adenosine deaminase (ADA) among patients with and without an $E$. coli positive test. ADA is a marker of cell mediated immunity, and ADA has been increased in the serum of patients with various diseases. These researchers observed a significant rise of ADA in $E$. coli positive group which indirectly supports the pathogenicity of this organism.

I concluded that the pathogenic role of these organisms (E. nana and $E$. coli) in immunocompetent individuals deserves further studies, but in patients with chronic renal hemodialysis insufficiency, both organisms were frequently reported (SEYRAFIAN S, et al., Applied Medical Informatics, 2011;29:31-36; AZAMI, et al., 2010) and there is a lot of evidence that can confirm the pathogenicity of these organisms in immunocompromised uremic patients, as mentioned above.

In conclusion, when we consider these organisms as parasites, as occurred in the article of Frederico F. GIL et al., this is not an error, but on the contrary, makes sense since the sampled population analyzed by these authors included patients undergoing hemodialysis, and therefore these uremic individuals developed a multi-dysfunctional pattern that affects different immune cells contributing to susceptibility increase of infections as well as to inflammatory responses.

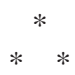

Summing up, there is a modern tendency, increasingly accepted among parasitologists and ecologists, to consider any association between different living species, configuring some degree of metabolic dependence between each participant, as a parasitic association, whether or not it results in injury to one of the components of the association. Thus, it is now considered as a parasitic association when not only the host suffers some injury due to the presence of the parasite, but also those forms of association that previously were classified as commensalism of symbiosis. 